\author{
James C. M. Chan · John D. Mahan \\ Howard Trachtman · Jon Scheinman \\ Joseph T. Flynn • Uri S. Alon • Marc B. Lande \\ Robert A. Weiss $\cdot$ Edward P. Norkus

\section{Vitamin E therapy in IgA nephropathy: a double-blind, placebo-controlled study}

Received: 22 August 2002 / Revised: 22 April 2003 / Accepted: 23 April 2003 / Published online: 12 August 2003

(C) IPNA 2003

J. C. M. Chan

Virginia Commonwealth University,

Richmond, Virginia, USA

J. C. M. Chan

University of Vermont College of Medicine,

Burlington, Vermont, USA

J. D. Mahan

Ohio State University,

Columbus, Ohio, USA

H. Trachtman

Long Island Jewish Hospital,

New Hyde Park, New York, USA

J. Scheinman

University of Kansas,

Kansas City, Kansas, USA

J. T. Flynn

University of Michigan,

Ann Arbor, Michigan, USA

J. T. Flynn

Montefiore Medical Center,

Albert Einstein College of Medicine,

Bronx, New York, USA

U. S. Alon

Mercy Children's Hospital,

Kansas City, Kansas, USA

M. B. Lande

University of Rochester,

Rochester, New York, USA

R. A. Weiss

New York Medical College,

Valhalla, New York, USA

E. P. Norkus

Our Lady of Mercy Medical Center,

Bronx, New York, USA

J. C. M. Chan ( $)$

The Barbara Bush Children's Hospital,

Maine Medical Center,

22 Bramhall St., Portland, ME 04102-3175, USA

e-mail: chanj@mmc.org

Tel.: +1-207-8712439, Fax: +1-207-8716272
Abstract IgA nephropathy is the world's most common primary glomerulonephropathy. Recent evidence in a rat model implicated excessive production of oxygen-free radicals in the pathogenesis and suggested that vitamin E-treatment ameliorated progression. We studied this antioxidant therapy on the glomerular filtration rate (GFR), proteinuria and hematuria in biopsy-proven $\operatorname{IgA}$ nephropathy in children. The duration of treatment or placebo was 2 years, with vitamin $\mathrm{E}$ treatment consisting of $400 \mathrm{IU} /$ day in children weighing $<30 \mathrm{~kg}$, and twice that dose for those $>30 \mathrm{~kg}$. We measured GFR at entry, midpoint and exit. At baseline and at 4-month intervals after randomization, urinary protein/creatinine ratios and urinalysis were examined. The mixed model procedure with $\log$ transformation was used in data analysis to test treatment difference as well as the potential time effect. Fifty-five patients were randomized and 38 completed at least 1 year of follow-up. At entry, the clinical characteristics were not different between the treatment and placebo groups. There was a trend toward better preservation of GFR in vitamin E-treated versus placebo patients, $127 \pm 50$ vs. $112 \pm 31 \mathrm{ml} / \mathrm{min} / 1.73 \mathrm{~m}^{2}$, respectively $(P=0.09)$. The urinary protein/creatinine ratio was significantly lower in the vitamin E-treated group vs. placebo; $0.24 \pm 0.38$ vs. $0.61 \pm 1.37(P<0.013)$. However, there was no difference in the prevalence of hematuria between the groups. Vitamin E treatment in our study patients was associated with significantly lower proteinuria, but no effect on hematuria. While there was a trend toward stabilization of GFR in the vitamin E-treated patients, longterm treatment and follow-up are needed to determine whether antioxidant therapy is associated with preservation of renal function in IgA nephropathy.

Keywords IgA nephropathy · Antioxidant - Vitamin E . Proteinuria $\cdot$ Glomerular filtration rate $\cdot$ Hematuria 


\section{Introduction}

The end-stage renal disease program of chronic dialysis/kidney transplantation costs the nation $\$ 15.64$ billion/year [1]. IgA nephropathy accounts for $10-30 \%$ of patients in end-stage renal failure $[2,3,4,5,6]$. The long-term prognosis in children, previously presumed to be less serious than in adults with this condition, has recently been shown to be no different, with $25 \%$ of children with biopsy-proven IgA nephropathy progressing to end-stage renal disease in 20 years $[7,8]$.

The pathogenesis of IgA nephropathy is unclear [9, 10] and there are no proven therapies that reverse the progressive glomerulosclerosis which leads to end-stage kidney disease [11]. Recently, we documented increased oxygen-free radical release in an experimental rat model of IgA nephropathy [12]. Administration of a diet that was modestly enriched in vitamin $\mathrm{E}$ ameliorated renal functional deterioration and prevented glomerular damage. This protective effect was associated with a decrease in renal cortical malondialdehyde content [12]. This demonstration that oxygen-free radical injury contributes to the pathogenesis of IgA nephropathy and that antioxidant therapy can decrease glomerular injury [12] is in accordance with recent studies which indicate that peripheral polymorphonuclear leukocytes isolated from patients with $\operatorname{IgA}$ nephropathy generate increased amounts of superoxide radicals $[13,14]$ and IgA-containing immune-complexes stimulate production of oxygen-free radicals by mesangial cells in situ [15]. In parallel with enhanced superoxide production, aggregated $\operatorname{IgA}$ induced $\mathrm{Fc} \alpha$ receptor expression in leukocytes [13, 14]. These findings were correlated with the severity of proteinuria in patients with $\operatorname{IgA}$ nephropathy $[13,14$, 16].

We conducted a pilot study consisting of an interventional human trial using a randomized, placebo-controlled prospective design in biopsy-proven IgA nephropathy from a network of seven pediatric nephrology programs.

\section{Materials and methods}

Study subjects and procedures

This pilot study was prospective, double blinded and placebo controlled. Institutional Review Board approval was obtained for each of the seven participating pediatric nephrology programs. Patients were approached by the investigator to participate in the study. The purpose and procedures of the investigation were explained to the parents or the legal guardian and to the child. Written informed consent obtained from the parent or guardian, and where appropriate from the child, was sent to the centralized Data Coordinating Center (DCC). The DCC reviewed the signed consent form, clinical record, and renal biopsy for entry into the study. Randomization to placebo or treatment arms was generated by a computer to achieve a balance between the two groups, so that baseline characteristics of gender, ethnic group, height, weight, blood pressure and geographic distribution were accounted for.

Primary $\operatorname{IgA}$ nephropathy, confirmed by the index renal biopsy at the participating center with $\operatorname{IgA}$ deposition in the mesangium, qualified for entry. Entry criteria also included patients with docu- mented hematuria (more than three erythrocytes per high-power field in spun urine sample) [17] on two occasions during the prerandomization period and a glomerular filtration rate between $20 \%$ and $100 \%$ of normal for age. The choice of a lower limit of glomerular filtration rate lessened the likelihood of a patient exiting to dialysis and/or transplantation during the period of the study. The age of entry was less than 21 years of age.

The exclusion criteria were as follows: (1) secondary IgA nephropathy associated with organ transplantation, HIV+, diabetes mellitus, lupus nephritis, Alport syndrome, anaphylactoid purpura nephropathy, chronic liver diseases (hepatitis, biliary tract obstruction), gastrointestinal diseases (celiac disease, Crohn disease, adenocarcinoma), respiratory diseases (chronic obstructive bronchiolitis, idiopathic interstitial pneumonia), dermatitis herpetiformis, mycosis fungoidis, leprosy, episcleritis, anterior uveitis, ankylosing spondylitis, relapsing polychondritis, schistosomiasis, Sjogren syndrome, monoclonal IgA gammapathy and pregnancy; (2) previous treatment with vitamin $\mathrm{E}$, corticosteroid, cyclosporin, tacrolimus, warfarin, persantin, phenytoin, fish oil, omega 3-polyunsaturated fatty acid, danazol, dapsone, dipyridamole, urokinase, sodium cromoglycate, plasmaphoresis, angiotensin-converting enzyme inhibitor, tonsillectomy or Cordyceps sinensis (Chinese herbal medicine); (3) pregnancy; and (4) hypertension, as defined vide infra.

The exit criteria were: (1) dialysis/transplantation, as well as hypertension (vide infra); (2) medical non-compliance (after two consecutive warnings), documented by self-admission, medication package counts, and serum vitamin E concentration; and (3) failure to report for two consecutive follow-up visits. The reasons for exit were reported to the Data Coordinating Center and the Principal Investigator. Within reason, patients who exited the study continued to be followed.

The primary endpoints were changes in GFR and proteinuria as indices of progression and response to therapy. The prevalence of hematuria was a secondary endpoint.

\section{Treatment}

Patients received one or two placebos or vitamin E capsules, which were identical in appearance. Children less than $30 \mathrm{~kg}$ body weight received one capsule of $400 \mathrm{IU}$ vitamin E/day; children of $30 \mathrm{~kg}$ body weight or above received two capsules of $400 \mathrm{IU} /$ day. Hoffman-La Roche Inc. provided both placebo and the vitamin E capsules. These were enclosed in 30-day medication packages (Remind-A-Pac, Southfield, MI) [18]. A back-up 1-month package was always made available for each patient at the respective clinics.

\section{Clinic visits and laboratory tests}

At entry these parameters were obtained: height, weight, blood pressure, physical examination, urinalysis of fresh early morning specimen, and urine protein to creatinine ratio, 24-h creatinine clearance, fasting serum electrolytes, urea nitrogen, creatinine and vitamin E.

Hypertension was defined by diastolic blood pressure exceeding the 95th percentile above normal for age documented on three occasions in a quiet and relaxed setting. Hypertension or the use of an antihypertensive medication was cause for exclusion or exit. All exited patients continued as per this protocol, but their data were separately analyzed.

At follow-up every 4 months, these parameters were obtained: height, weight, blood pressure, physical examination, early morning urine protein/creatinine, urinalysis, serum electrolytes, urea nitrogen, creatinine and vitamin E. At annual intervals or study exit 24-h creatinine clearance was repeated. 
Microscopic urinalysis

The early morning, "clean catch" or clean-void and mid-stream sample was the specimen of choice [17]. The analysis was done by the investigator at the participating center. After mixing the fresh specimen, $10-15 \mathrm{ml}$ of urine was centrifuged at $2000 \mathrm{rpm}$ for $5 \mathrm{~min}$. The supernatant fluid was poured off and the resuspended sediment mixed. A drop of sediment on a clean slide was prepared for microscopic examination in subdued light [17]. The number of red cells per high-power field was counted and reported. Red cells, dysmorphic red cells, red cell casts and other elements [17] were recorded.

Routine chemistry methods for urinalysis, urine protein and creatinine clearances

Routine laboratory procedures for dipstick urinalysis, protein and creatinine of an early morning voiding were performed at the participating centers. The standard 24-h creatinine clearances for glomerular filtration rate were determined $[19,20]$.

\section{Serum vitamin E concentration}

Serum vitamin E concentration was determined as an index of compliance, using the high-pressure liquid chromatography (HPLC) method [21]. Specimens for vitamin E concentrations were obtained at the participating centers and sent to the DCC for analysis.

Statistical methods

The biostatistician was blinded to the treatment code, which was not broken until data analysis was completed. The urinary protein to creatinine ratio was analyzed by the mixed model procedure [22]. The analysis was based on the log transformation of the ratio [23] and both the treatment difference and the potential time effects were examined.

In analyzing the prevalence of hematuria, two approaches were used: (1) either heme positive or heme negative on a dipstick of a fresh urine sample or (2) positive or negative for three or more red blood cells per high-power field in a fresh urine sample. The chisquare test was used to test the differences between the placebo and treatment arms.

The creatinine clearances were analyzed by Student's $t$-test [23] based on the log transformed data.

\section{Results}

From 1 January 1997 to 1 August 2000, 62 patients with IgA nephropathy were evaluated and 55 who met the entry and exclusion criteria consented to enroll in the study. Twenty-eight were randomized to receive placebo and 27 received vitamin $\mathrm{E}$.

\section{Baseline characteristics}

The clinical and laboratory characteristics of the two groups were similar at randomization (Table 1) in terms of gender, ethnic group, height, weight, blood pressure, prevalence of hematuria, degree of proteinuria and creatinine clearance.
Table 1 Baseline characteristics at randomization (means \pm SD) ( $R B C / H P F$ red blood cell per high-power field)

\begin{tabular}{lcc}
\hline & $\begin{array}{c}\text { Treatment } \\
(n)(\%)\end{array}$ & $\begin{array}{c}\text { Placebo } \\
(n)(\%)\end{array}$ \\
\hline Male & $21(75)$ & $19(70)$ \\
Female & $7(25)$ & $8(30)$ \\
Race or ethnic group & & \\
Asian & $3(11)$ & $1(4)$ \\
Black & $1(4)$ & $2(7)$ \\
Other & $1(4)$ & 0 \\
White & $23(82)$ & $24(89)$ \\
Age (years) & $11 \pm 4$ & $12 \pm 3$ \\
Height $(\mathrm{cm})$ & $141 \pm 47$ & $146 \pm 36$ \\
Weight $(\mathrm{kg})$ & $58 \pm 21$ & $54 \pm 23$ \\
Blood pressure & & \\
Systolic $(\mathrm{mmHg})$ & $118 \pm 13$ & $119 \pm 17$ \\
Diastolic $(\mathrm{mmHg})$ & $69 \pm 10$ & $67 \pm 14$ \\
Hematuria & & \\
Dipstick + & $25(89)$ & $22(81)$ \\
$>3$ RBC/HPF & $15(54)$ & $21(78)$ \\
$<3$ RBC/HPF & $4(14)$ & $3(11)$ \\
Not done & $9(32)$ & $3(11)$ \\
Proteinuria & & \\
Dipstick + & & \\
Dipstick - & $23(82)$ & $23(85)$ \\
Protein/creatinine $(\mathrm{mg} / \mathrm{mg})$ & $5(17)$ & $4(15)$ \\
Creatinine clearance $\left(\mathrm{ml} / \mathrm{min} / 1.73 \mathrm{~m}^{2}\right)$ & $116 \pm 32$ & $106 \pm 38$ \\
\hline & &
\end{tabular}

\section{Study outcome}

The serum $\alpha$-tocopherol concentration increased significantly $(P<0.001)$ from $0.84 \pm 0.25 \mathrm{mg} / \mathrm{dl}($ mean \pm SD) in the placebo patients to $1.85 \pm 0.77$ in the treated patients. The creatinine clearances at the end of the study showed values of $112 \pm 31 \mathrm{ml} / \mathrm{min} / 1.73 \mathrm{~m}^{2}$ in the placebo versus values of $127 \pm 50 \mathrm{ml} / \mathrm{min} / 1.73 \mathrm{~m}^{2}$ in the treated patients $(P=0.09)$. None suffered a significant decline in GFR.

The data showed that there was no difference in the prevalence of hematuria, either tested by theme reaction on dipstick or by red blood cells per high-power field. The urinary protein to creatinine ratio showed a significant drop $(P=0.013)$ from the placebo group $(0.61 \pm 1.37 \mathrm{mg} / \mathrm{mg})$ to the values in the treated group $(0.24 \pm 0.38 \mathrm{mg} / \mathrm{mg})$.

No patients exited the study to end-stage kidney disease, dialysis or transplantation. Patients dropped out of the study due to self-administration of vitamin $\mathrm{E}$ and failure to keep two consecutive follow-up clinic appointments.

\section{Safety}

There were no complaints or untoward complications from either group of patients. 


\section{Discussion}

In this investigator-initiated and NIH-funded pilot study, vitamin E therapy was associated with a significant reduction in the proteinuria of children with biopsy-proven $\operatorname{Ig}$ A nephropathy, but with no significant changes in the prevalence of hematuria. The results raise the possibility of a renoprotective effect of vitamin E in IgA nephropathy.

In a recent study, Chitalia et al. [24] showed that spot urine protein to creatinine ratio (between 0.26 and $3.20 \mathrm{mg} / \mathrm{mg}$ ) agrees closely with $24-\mathrm{h}$ urine protein along a wide range of renal function and glomerular diseases. Their study [24] strengthens the validity of our using early morning, spot urine protein to creatinine ratio. Our pilot data, therefore, support the promise of a fullscale trial to test the efficacy of antioxidants in long-term treatment of IgA nephropathy, including a focus on urinary microalbuminuria [25] and new molecular biomarkers, e.g., urinary nephrin genes [26], as indices of renal injury or recovery.

The difficulty in using an antioxidant, e.g., vitamin E, in clinical trials lies in the fact that patients often want to self-administer this over the counter, inexpensive product, with no clinically relevant side effects. However, the significantly low serum $\alpha$-tocopherol concentrations in the placebo patients compared to the higher values in the treated patients attest to patient compliance. It is a credit to the patients' families and the bond with the clinical investigators that medical compliance was excellent throughout the study.

In experimental IgA nephropathy, Trachtman et al. [12] demonstrated that vitamin E treatment was associated with a significant reduction of proteinuria, as we now confirm in this pilot study. In contrast to the unchanged prevalence of hematuria in our human study, the animal studies of Trachtman et al. [12] showed a significant reduction in the incidence of hematuria. Whether doubling or tripling of the current dose of vitamin E might have an effect on the prevalence of hematuria is conjectural. A dose response study, similar to that conducted in experimental IgA nephropathy [27], is outside the purview of our study aim. A dose response study will require a larger consortium of centers to provide the requisite number of patients.

Similar to our TGF $\beta 1$ data for our rat model of $\operatorname{IgA}$ nephropathy [12], increased glomerular TGF $\beta 1$ mRNA in patients with $\operatorname{IgA}$ nephropathy has been demonstrated by Naka et al. [16]. The progression of IgA nephropathy may result from overexpression of TGF $\beta 1$ leading to mesangial matrix expansion, interstitial fibrosis, and glomerulosclerosis. We hypothesize that the interception of autocrine activation of TGF $\beta 1$ by the natural antioxidant, vitamin $\mathrm{E}$, may check disease progression in $\operatorname{IgA}$ nephropathy [12].

Finally, creatinine clearance remained well preserved in both placebo and treated groups. However, the estimate of GFR used in this study may not be sensitive enough to detect loss of renal function over the relatively short duration of observation of our trial [26]. For IgA nephropathy, a slowly progressive disease where $25-30 \%$ of patients continue over a quarter century to end-stage renal disease $[2,3,4]$, a full-scale, longer duration clinical trial with more accurate measurement of glomerular filtration rate [28] will be needed for valid generalization.

It should be noted that the disease in our patients was in the early and mild stages. There is a need to extend these findings to more severely affected patients with IgA nephropathy and to follow such patients for an extended period of time.

The data of the present pilot study were not designed to test this question but may lead to the use of vitamin $\mathrm{E}$ either alone or as an adjunct medication in early $\operatorname{Ig} \mathrm{A}$ nephropathy to slow the rate of progression of this common primary glomerular disease.

Acknowledgements Sung C. Choi, $\mathrm{PhD}$ (Department of Biostatistics, Virginia Commonwealth University, Richmond, VA), provided statistical support. The study was supported by grants from the National Institutes of Health (R01 DK50419, DK97761) and the General Clinical Research Center (M01 RR00065). HoffmanLaRoche, Inc., supplied vitamin E and placebo. We thank K.C. Lin for research and Betty Timozek for secretarial support.

\section{References}

1. Executive Summary (1999) United States Renal Data System 1996 Annual Data Report. Am J Kidney Dis 34:S9-S19

2. Welch TR, Fryer C, Shelly E, Witte DP, Quinlan M (1992) Double-blind, controlled trial of short-term prednisone therapy in immunoglobulin A glomerulonephritis. J Pediatr 121:474477

3. Waldo FB, Wyatt RJ, Hogg RJ, Andreoli SP, Milliner DS (1998) Current concepts and controversies in IgA nephropathy. Pediatr Nephrol 12:498-504

4. Donadio JV Jr, Bergstein EJ, Offord KP, Spencer DC, Holley KE (1994) A controlled trial of fish oil in IgA nephropathy. N Engl J Med 331:1194-1199

5. Donadio JV, Grande JP (2002) IgA nephropathy. N Engl J Med 347:738-748

6. Droz D, Karmar A, Nawar T, Noel LH (1984) Primary IgA nephropathy: prognostic factors. Contrib Nephrol 40:202207

7. Wyatt RJ, Emancipator SN, Kon V, Waldo FB, Donadio J, Grande JP, Andreoli SP, Glassock RJ (1997) IgA nephropathy databank: development of a system for management of renal biopsy acquired data. Am J Kidney Dis 29:817-828

8. Wyatt RJ, Kritchevsky SB, Woodford SY, Miller PM, Roy S III, Holland NH, Jackson R, Bishof NA (1995) IgA nephropathy: long-term prognosis for pediatric patients. J Pediatr 127: 913-919

9. Ibels LS, Gyory AZ, Caterson RJ, Pollock CA, Mahony JF, Waugh DA, Rogers SD, Coulshad S (1997) Primary IgA nephropathy: natural history and factors of importance in the progression of renal impairment. Kidney Int 61:S67-S70

10. Galla JH (1995) IgA nephropathy. Kidney Int 47:377-387

11. Scheinman JI, Trachtman H, Lin CY, Langman CB, Chan JCM (1997) IgA nephropathy: to treat or not to treat? Nephron $75: 251-258$

12. Trachtman H, Chan JCM, Chan W, Brandt R, Wakely P, Futterweit S, Maesaka J, Ma C (1996) Vitamin E ameliorates renal injury in an experimental model of immunoglobulin A nephropathy. Pediatr Res 40:620-626

13. Kashem A, Endoh M, Nomoto Y, Sakai H, Nakazawa H (1994) Fco R expression on polymorphonuclear leukocyte and 
superoxide generation in $\operatorname{Ig}$ A nephropathy. Kidney Int 45: 868-875

14. Kashem A, Endoh M, Yano N, Yamauchi F, Nomoto Y, Sakai H, Pronai L, Tanaka M, Nakazawa H (1997) Glomerular Fc alpha $\mathrm{R}$ expression and disease activity in IgA nephropathy. Am J Kidney Dis 30:389-396

15. Chen A, Chen WP, Sheu LF, Lin CY (1994) Pathogenesis of IgA nephropathy: in vitro activation of human mesangial cells by IgA immune complex leads to cytokine secretion. J Pathol 173:119-126

16. Naka R, Suzki D, Miyazzaki M (1993) TGF- $\beta$ mRNA and tissue damage in glomeruli from patients with $\operatorname{IgA}$ nephropathy. J Am Soc Nephrol 4:685 (abstract)

17. Graff L (1983) A handbook of routine urinalysis. JB Lippincott, Philadelphia

18. Chan JCM, McEnery PT, Chinchilli VM, Abitbol CL, Boineau FG, Friedman AL, Lum GM, Roy S III, Ruley EJ, Strife CFL (1994) A prospective, double-blind study of growth failure in children with chronic renal insufficiency and the effectiveness of treatment with calcitriol versus dihydrotachysterol. J Pediatr 124:520-528

19. Santos F, Orejas G, Foreman JW, Chan JCM (1991) Diagnostic workup of renal disorders. Curr Probl Pediatr 21:48-74

20. Chan JCM, Sharpe AR (1982) Glomerular filtration rate in children with advanced chronic renal failure: methods of determination and clinical applications. Am J Nephrol 2:46-55
21. Brandt RB, Kaugars GE, Riley WT, Bei RA, Silverman S Jr, Lovas JG, Dezzutti BP, Chan W (1996) Evaluation of serum vitamin and tissue levels of alpha-tocopherol. Biochem Mol Med 57:64-66

22. Zeger SL, Liang KY (1992) An overview of methods for the analysis of longitudinal data. Stat Med 11:1825-1839

23. Ott RL (1992) An introduction to statistical methods and data analysis, 4th edn. Duxbury Press, Belmont, CA, pp 454-460

24. Chitalia VC, Kothari J, Wells EJ, Livesey JH, Robson RA, Searle M, Lynn KL (2001) Cost-benefit analysis and prediction of 24-hour proteinuria from the spot urine protein-creatinine ratio. Clin Nephrol 55:436-447

25. Houser MT (1984) Assessment of proteinuria using random urine samples. J Pediatr 104:845-848

26. Chiang PW, Schneider A, Borgnat S, Gaub MP, Oudet P, Kurnit DM, Jacqmin D (2000) Molecular analysis of urine sediment for the followup of urinary tract cancer. J Natl Cancer Inst 92:1779-1780

27. Kuemmerle NB, Krieg RJ Jr, Chan W, Trachtman H, Norkus EP, Chan JCM (1999) Influence of $\alpha$-tocopherol over the time course of experimental IgA nephropathy. Pediatr Nephrol 13:108-112

28. Balachandran S, Toguri AG, Petruseck TW, Abbot LC (1991) Comparative evaluation of quantitative glomerular filtration rate measured by isotopic and non-isotopic methods. Clin Nucl Med 6:150-153 